APPLICABILITY OF GOLDEN RECTANGLE IN FAÇADE OF BUILT FORM

\title{
Architectural Research
}

Ar. Harshika Assistant Professor, SOA, IPS Academy, Knowledge Village, Rajendra Nagar, A. B. Sahay*

\section{Ar. Neelam} Kushwah

Road, Indore-452012, M. P. * Corresponding Author

\begin{abstract}
All of us want to promote pleasing architecture but is there a clear theory that explains what makes a design good. Why do some buildings look pleasing to us while the others not so much? Why do a few of them give us a sense of wellbeing whereas a few of them make us feel out of place. Architecture never has a single answer and is very subjective. It is evident that there could be a tangible relationship between the visual aspect of a building and the intangible that is the way we feel about it. This research tries to understand these tangible characteristics of a built form and tries to objectify aesthetics by analyzing it through the lens of scale and proportion.

"Geometry existed before creation" - Johan Kepler

"Nature seems to be written in the language of mathematics"- Galileo Galilei

These statements form the basis of this research. It will start with the study of the relationship of aesthetics of façade and their proportions by overlaying the guiding principles attached to these attributes on several built forms. Once established as to how through history buildings have related to different simple and complex equations the research moves on to perceive a certain number of buildings in current scenario. These buildings may or may not have been built on some geometrical guiding principles. Later through survey the research will try and identify whether or not an aesthetically pleasing building has some relationship with scale. It will try and identify the exact equation that guided the form of the building. The relationship between proportion and aesthetics will be established by running experiments, overlaying and calculating proportion theories on to the façade of that particular built form.
\end{abstract}

\section{KEYWORDS}

Proportion, Façade, Golden Rectangle

\section{INTRODUCTION}

\section{Objective of the Study}

Henry Wotton, an English writer had translated 'de Architectura' written by Vitruvius and illustrated that a building can look good only when it has these three characteristics-

- Commodity (usefulness),

- Firmness (solidity or strength)

- Delight(beauty)

Proportion has a huge role to play when it comes to the aesthetics of a built form. The three points discussed serves as a rule book for making a pleasant building with a healthy environment. The proportion makes a place inviting, cozy or repulsive.

\section{The objectives of the research are as follows-}

- To get an understanding of the subject through literature study

- To identify built forms for research purpose

- Narrow down research and survey methodology

- Primary research on the built forms identified

- Comparing and concluding the research

\section{AIM OFTHE STUDY}

The research will try to quantify the aesthetics of the façade of a built form and prove that geometry and scale plays a very crucial role in deciding whether or not a building is visually pleasing.

\section{Methodology Research Design}

- Study of buildings in different era of history and understand their relationship with the guiding equation or scale

- Identifying ten contemporary built forms for research analysis

- Overlaying the façade of these built forms to the guiding equation

- Floating a questionnaire survey in the Architecture fraternity

- Comparing the results from Survey and Personal analysis

- Drawing conclusion on the basis of comparative results

\section{Limitation}

This research will concentrate on a select few buildings and run the test of Golden ratio on them. It will concentrate on the characteristics of the façade of the built form only. It does not include the planning criteria of any of the identified projects. It will not take into consideration the role of perspective and how far or close an observer is to the built form.

\section{Need and concern for the topic}

The research yearns to objectify the aesthetics of a built form and tries to relate it to the set proportion theories in architecture and arts that have been in practice through centuries. It tries to judge and access the drama that has been created over a long period of time about proportion in nature in general to the proportions in architecture. It will prove whether or not really these proportion theories play a role and the extent of the role the same in visual relationship of built form.

\section{Definitions}

The concept of Proportion was introduced centuries ago and ever since numerous proportion theories have been proposed. When we look at them closely, we figure out that most of these theories are inter related and have been derived from prevailing theories at that time or in antiquity. From Phi to Le Modular proposed by Le Corbusier, every theory is inter-relatable.

Scale and Proportion is defined in Architecture Form, Space and Order by Francis D.K. Ching as follows-

"While scale alludes to the size of something compared to a reference standard or to the size of something else, proportion refers to the proper or harmonious relation of one part to another or to the whole."

\section{Chronology of theories}

- Phidias- 500 BC - 432 BC studied Phi applied it to sculptures for the Parthenon

- Plato- $(428 \mathrm{BC}-347 \mathrm{BC})$

- $\operatorname{Euclid}(365 \mathrm{BC}-300 \mathrm{BC})$ Mean ratio

- Vitruvius-De Architectura 13-15 BC

- Leonardo Fibonacci-1200AD Fibonacci Series

- Alberti 1407-1472

- Vitruvian Man by Leonardo da Vinci 1487

- Palladian Ratio

- Divine Proportion term used in the 1500

- "Golden Ratio" was coined in the 1800 's by Martin Ohm

- Le Modular- Le Corbusier 1942-1948

Phi

A Greek scholar Phidias (500 BC - 432 BC) had decoded the number phi and used it in proportions of various famous buildings that he built, e.g.- Parthenon. It has also been studied that the number or letter Phi along with Pi had already been used by people of Egypt in antiquity. 
Actually, the term "Phi" was used only after the 19th century when the Mathematician from USA Mark Barr used phi $(\Phi)$. Phi is the Greek equivalent to the letter $\mathrm{F}$

Value of Phi: $\Phi=1.6180$ and $\varphi=0.6180 \ldots=1 / \Phi$

\section{Golden Rectangle}

De Divina Proportione or the Golden proportion or section states that when and segment is divided into two unequal parts, the ratio of the smaller part to the bigger part is the same as the ratio between the bigger part and the full segment. It is a phenomenon that has been used in art work and buildings alike.

Martin Ohm (1792-1872) was the first person to use the term "golden ratio". He called it the "goldener schnitt" (Die reine ElementarMathematik 1918)

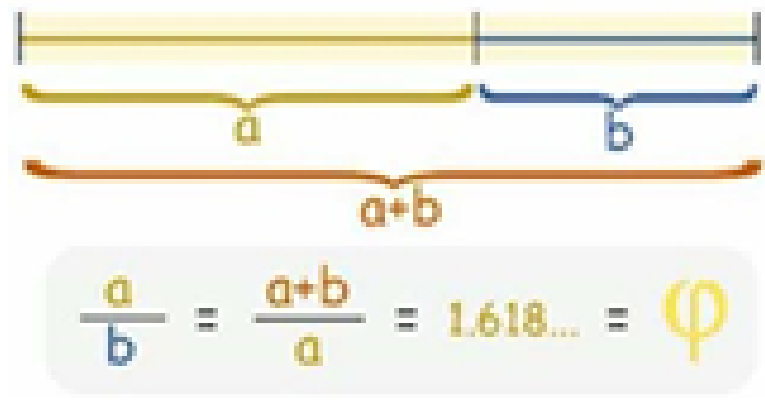

Fig 1: Rectangle growing in geometric progression

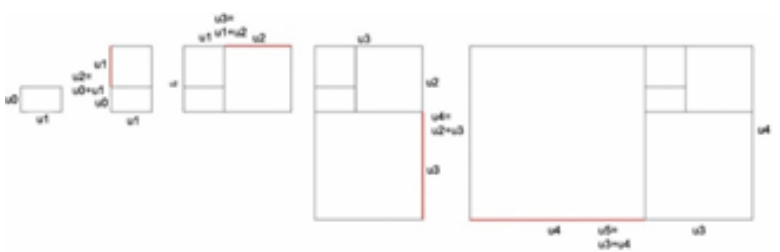

Fig 2: Parallelepiped growing in a geometric progression
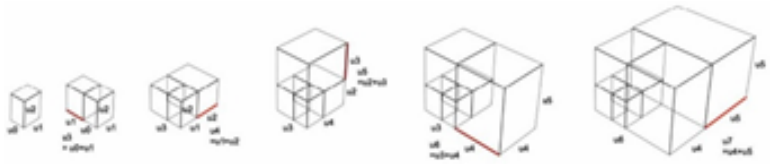

Source: Modularity and Proportions in Architecture and their Relevance to a Generative Approach to Architectural Design -By Marie-Pascale Corcuff

\section{MATERIALS AND METHODS}

\section{Survey}

A questionnaire was floated amongst members of the fraternity and related fraternity to collect responses to narrow down on the built forms to be analyzed. The buildings picked initially did not follow a certain pattern and it had a mix of commercial, residential and educational buildings.

\section{Survey analysis}

The following 35 buildings were included in the survey. Participants were asked to rate the buildings and the result was converted and analyzed and the percentage of people who thought the building was aesthetically pleasing has been specified below. The sample size was about 160 and the participants were either practicing architects or architecture students.

1. BurjAlArab, Dubai- $84 \%$

2. Taj Mahal- $92 \%$

3. Church at Firminy, France- $41 \%$

4. La Pedrera (Casa Mila) Barcelona- $56 \%$

5. Lal Bagh Palace- $\mathbf{4 4 \%}$

6. Sangath- $70 \%$

7. 0-14 Tower Dubai- $25 \%$

8. Guggenheim- Bilbao, Spain- $37 \%$

9. Habitat $67-65 \%$

10. City of dreams, Macau- $50 \%$

11. Le Centre Pompidou- $34 \%$
12. Parthenon- $71 \%$

13. Hearst Building- $78 \%$

14. Unite d'habitation- $79 \%$

15. Antilia- $32 \%$

16. Ramkrishna House- $28 \%$

17. Apollo Premier- 67\%

18. Eiffel Tower- $87 \%$

19. New Academy of Art, China- $27 \%$

20. New Art Museum, NY- $50 \%$

21. AT \& T building- $68 \%$

22. Qatar National Convention Center- $55 \%$

23. Guangzhou Circle- $59 \%$

24. Pantheon- $75 \%$

25. The Imperial Mumbai $-65 \%$

26. Milan Cathedral- $80 \%$

27. Dancing House- $34 \%$

28. VIA West 57, NY- $64 \%$

29. Vanna Venturi House- $66 \%$

30. The Museum of Tomorrow, Rio de Janeiro- $50 \%$

31. CCTV Headquarters, Beijing- $63 \%$

32. Glass House- $73 \%$

33. Visvesvaraya Tower, Bangalore- $28 \%$

34. Hagia Sophia- $84 \%$

35. Geisel Library- $79 \%$

The 10 buildings that have been highlighted was selected to run the experiments and tests

\section{Table1- Details Of Buildings Selected RESULTS AND DISCUSSIONS \\ Burj Al Arab, Dubai}

Golden Rectangle sits perfectly on the sail side elevation. Taking the base, mid-point of exoskeleton structure and the top of the tower.

\begin{tabular}{|c|c|c|c|c|c|}
\hline me of Building & Poll Result & Location & Architect & Year of construction & Architectural Style \\
\hline \begin{tabular}{|l|l|} 
Burj Al Arab \\
Tij Mhal
\end{tabular} & 848 & $\begin{array}{l}\text { Oubai, United Arab Emirates } \\
\text { Arata }\end{array}$ & 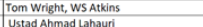 & & \\
\hline Taj Mahal & & Agra, India & Ustad Ahmad Lahauri & $1632-53$ & Mughal architecture \\
\hline Eiffel Tower & $87 \%$ & Paris, France & $\begin{array}{l}\text { Gustave Eiffe( IEngineer), } \\
\text { Stephen Savvestre }\end{array}$ & 1887-89 & Modern \\
\hline Milan Cathedral & $80 \%$ & Milan, taly & Fabbrica del Duomo & 1387 & Gothic \\
\hline & $84 \%$ & Istanbul & $\begin{array}{l}\text { |lisidore of Miletus, Anthemius of Tralles } \\
\text { (Mathematician, Physicist) }\end{array}$ & & chitecture \\
\hline 0-14 Tower & $25 \%$ & Dubali, United Arab Emirates & Jesse Reiser, Nanako Umemoto & 2009 & Contemporary \\
\hline Antilia & $32 \%$ & Mumbai, India & Perkins and Will & 2010 & Contemporary \\
\hline \begin{tabular}{|l|} 
Ramarkisisna House \\
Apollo Premier
\end{tabular} & 2887 & Anmedabad, India & 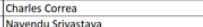 & 1964 & $\begin{array}{l}\text { Modern } \\
\text { Contempo }\end{array}$ \\
\hline al Bagh Palace & $44 \%$ & \begin{tabular}{|l} 
IIndore, India \\
Indore, India
\end{tabular} & $\begin{array}{l}\text { Novendd Srivastava } \\
\text { Under the vuidance of Tukojirao Holkz }\end{array}$ & 1886 & 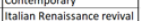 \\
\hline
\end{tabular}

\section{Taj Mahal, Agra}

References seen in the total height and width of the built form. Cross references at intermediate points on the minarets

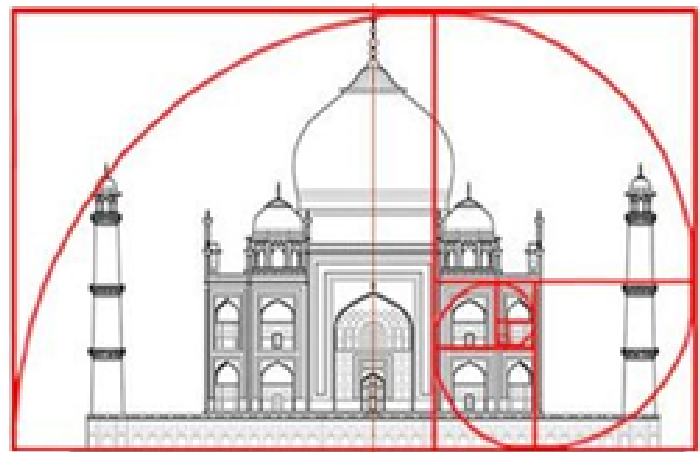

\section{Eiffel Tower, Paris}

It sits perfectly on the structure with a major reference point at the 2 nd deck.

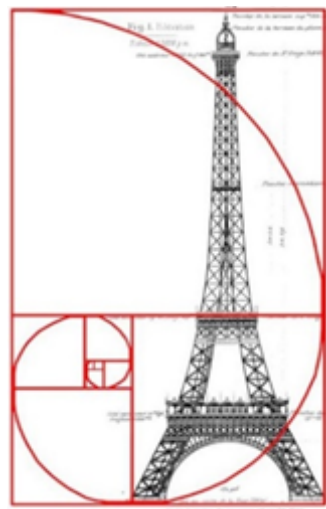




\section{Milan Cathedral, Milan}

The Golden rectangle sits perfectly on it

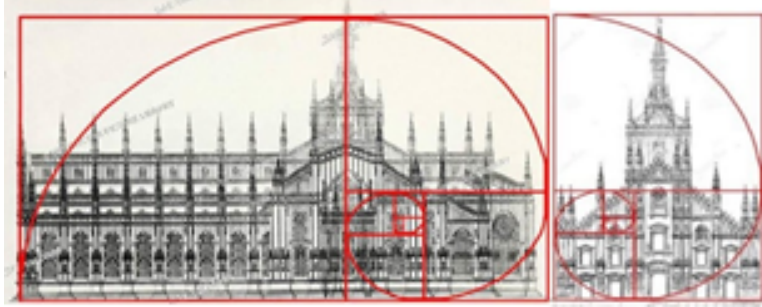

Hagia Sophia, Istanbul

A weak Interpretation of Golden ratio found

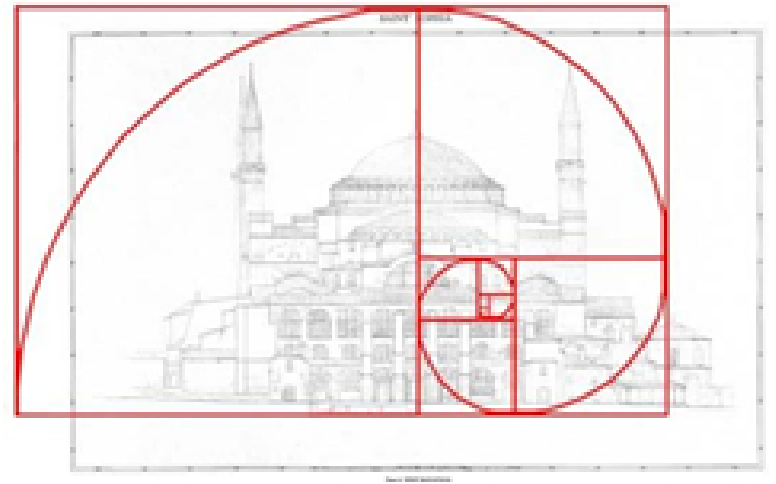

Burj Al Arab, Dubai

Golden Rectangle sits perfectly on the sail side elevation. Taking the base, mid-point of exoskeleton structure and the top of the tower.

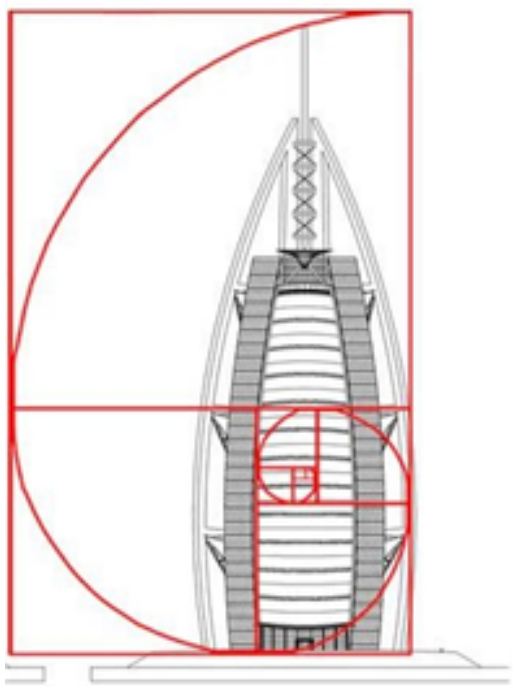

Antilia, Mumbai

Weak representation of Golden ratio

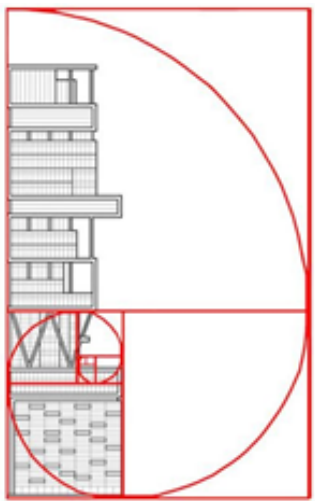

Ramkrishna House, Ahmedabad
Visible partially in the front façade of the building

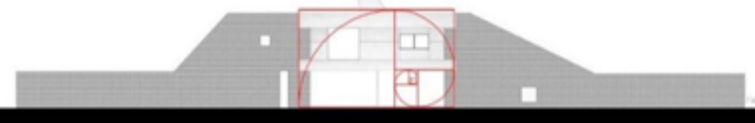

Apollo Premier, Indore

Golden rectangle sits perfectly on the side elevation as well as the front elevation.
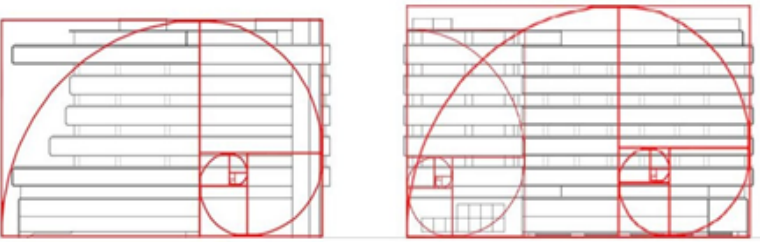

\section{O-14 Tower, Dubai}

Weak Interpretation of Golden ratio observed. Parts of the building may fall into the category though.

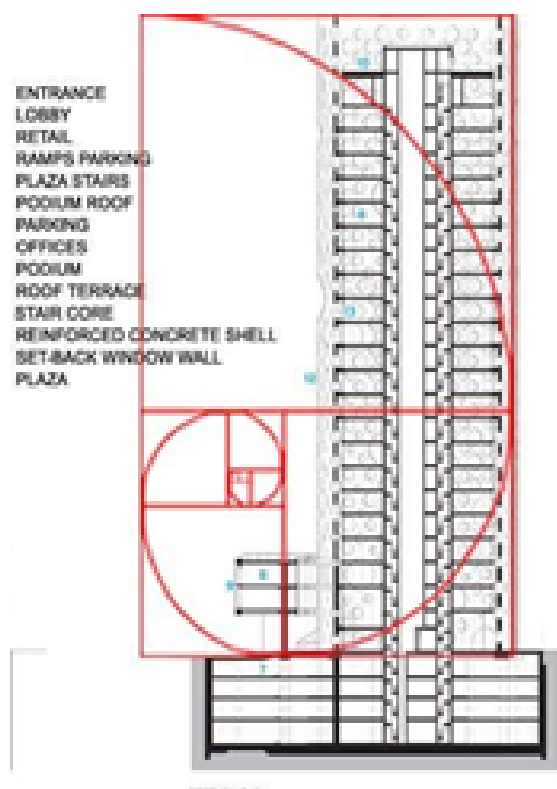

Lal Bagh Palace, Indore

Weak representation of Golden Ratio

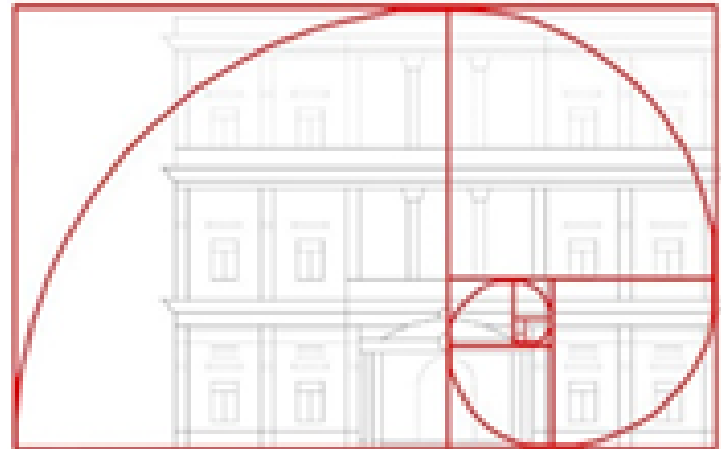

\section{CONCLUSIONS}

Going back to the Survey result, the following buildings were the most aesthetically pleasing to the participant.

Blues were the top of the chart; Reds were the bottom of the chart and Greens were two Indore buildings that were taken up for analysis

1. Taj Mahal- $92 \%$

2. Eiffel Tower- $87 \%$

3. Burj Al Arab, Dubai- $84 \%$

4. Hagia Sophia- $84 \%$

5. Milan Cathedral- $80 \%$

6. Apollo Premier- 67\% 
7. Lal Bagh Palace- $44 \%$

8. Antilia-32\%

9. Ramkrishna House- $\mathbf{2 8 \%}$

10. 0-14 Tower Dubai- 25\%

When we compare these results to the experiments run on each of these buildings, we realize that-

Taj Mahal, Eiffle Tower, Burj Al Arab and Milan Cathedral show close relationship with the golden rectangle as expected. The only anomaly was Hagia Sophia and Apollo Premier where in, the former should have sat perfectly on the proportions of golden rectangle and the latter not so much but the complete opposite happens. That makes us ponder whether or not there are other factors in play.

- Do we really see any building in pure elevation ever?

- How important is the role of Material, Play of Colours, finishes etc.?

- Does emotional attachment play a role?

- Does "Symbolism" play a role?

We may further the research and broaden the scope and perspective at a later stage and find out more.

\section{ACKNOWLEDGEMENTS}

I thank Ar. Prof. Manita Saxena, Ar. Suman Sharma and Ar. Sachin

Paliwal for their guidance.

\section{REFERENCES}

[1] Nelly Shafik Ramzy, El Masaeed, The Dual Language of Geometry in Gothic Architecture: The Symbolic Message of Euclidian Geometry versus the Visual Dialogue of Fractal Geometry, Peregrination- Journal of Medieval Art and Architecture, Autumn 2015

[2] Francis D. K. Ching, Architecture Form, Space \& Order, Fourth Edition

[3] Jay Kappraff, Systems of Proportion in Design and Architecture and their relationship to Dynamical Systems Theory, Bridges Mathematical Connections in Art, Music, and Science

[4] Marie-Pascale Corcuff, Modularity and Proportions in Architecture and their Relevance to a Generative Approach to Architectural Design, Nexus Netw J 14 (2012) 53-73

[5] Ar. Gaurav Gangwar, Principles and Applications of Geometric Proportions in Architectural Design, Journal of Civil Engineering and Environmental Technology, April- June 2017

[6] Michela Rossi, P. H. Scholfield: Review of The Theory of Proportion in Architecture, Cambridge University Press, Nexus Network Journal Architecture and Mathematics 2011 